\title{
Codex Chantilly, Bibliothèque du Château de Chantilly, Ms. 564, Introduction, Fac-similé, Edité par Yolanda Plumley et Anne Stone
}

\section{G. Matteo Roccati}

\section{(2) OpenEdition}

12 Journals

\section{Édition électronique}

URL : http://journals.openedition.org/studifrancesi/7852

DOI : ERREUR PDO dans /localdata/www-bin/Core/Core/Db/Db.class.php L.34 : SQLSTATE[HYO00]

[2006] MySQL server has gone away

ISSN : 2427-5856

\section{Éditeur}

Rosenberg \& Sellier

Édition imprimée

Date de publication : 1 juillet 2009

Pagination : 377

ISSN : 0039-2944

\section{Référence électronique}

G. Matteo Roccati, "Codex Chantilly, Bibliothèque du Château de Chantilly, Ms. 564, Introduction, Facsimilé, Edité par Yolanda Plumley et Anne Stone », Studi Francesi [En ligne], 158 (LIII | II) | 2009, mis en ligne le 30 novembre 2015, consulté le 08 janvier 2021. URL : http://journals.openedition.org/ studifrancesi/7852 ; DOI : https://doi.org/10.4000/studifrancesi.7852

Ce document a été généré automatiquement le 8 janvier 2021.

\section{(†)

Studi Francesi è distribuita con Licenza Creative Commons Attribuzione - Non commerciale - Non opere derivate 4.0 Internazionale. 


\title{
Codex Chantilly, Bibliothèque du Château de Chantilly, Ms. 564, Introduction, Fac-similé, Edité par Yolanda Plumley et Anne Stone
}

\author{
G. Matteo Roccati
}

\section{RÉFÉRENCE}

Centre d'Études Supérieures de la Renaissance, Codex Chantilly, Bibliothèque du Château de Chantilly, Ms. 564, Introduction, Fac-similé, Edité par Yolanda PLUMLEY et Anne STONE,

Turnhout, Brepols, 2008 («Epitome musical»), 2 vols, pp. 212 et fac-similé du manuscrit.

1 Réalisé vraisemblablement en Italie dans la deuxième décennie du $\mathrm{xv}^{\mathrm{e}}$ siècle, «reconnu depuis longtemps comme l'un des plus importants recueils de musique française de la fin du XIV e siècle» (p. 13), ce manuscrit est un témoin «à la fois du rayonnement de la chanson de cour française hors de son territoire d'origine, et de la place de la musique dans le milieu de cour pour lequel elle fut composée» (p. 98). Il contient 70 ballades, 17 rondeaux, 13 virelais, une chanson et 13 motets, en français et en latin, parmi lesquels 61 pièces sont des unica: «écrites par des compositeurs peu connus - voire inconnus en dehors de cette source, certaines comptent parmi les exemples les plus élaborés de la notation dite de l'Ars subtilior, portant ainsi témoignage des expériences faites par les compositeurs des dernières décennies du XIV siècle dans la symbolisation du rythme» (p. 13).

2 L'introduction (en français et en anglais, les textes se suivent pp. 11-98 et 99-182) fait le point sur nos connaissances au sujet du codex. En premier lieu elle retrace l'histoire de son étude depuis l'acquisition du manuscrit par Henri d'Orléans, duc d'Aumale, en 1861. Elle donne ensuite la description physique du manuscrit en traitant notamment les points suivants: la reliure et l'ordre de copie des textes, la préparation du corpus 
principal, les copistes, la préparation de l'index et du bifolio de Cordier (un bifolio ajouté dès l'origine dans lequel les textes sont présentés en forme figurée, tels des calligrammes), la page de titre et les dessins marginaux. L'examen porte ensuite sur le répertoire - chansons et motets - et les attributions, avant d'aborder la question du copiste et de ses modèles à partir des indices fournis par les erreurs, les corrections, la mise en page, la notation et la copie des textes. Enfin est examinée la relation entre le manuscrit et Florence: avant 1430 il a été à l'origine de la copie de certaines pièces françaises du chansonnier florentin Panciatichi 26 et il a appartenu tout d'abord au poète et banquier florentin Francesco di Altobianco degli Alberti qui l'a offert à la famille Spinelli en 1461 (l'histoire de ces personnages est tracée à partir de nouvelles recherches d'archives).

3 Le volume comporte encore l'inventaire des textes par cahiers, avec quelques indications essentielles (titre, attribution, nombre de voix, forme, autres témoins, remarques; pp. 183-200), et la bibliographie.

4 Le fac-similé est précédé de la Table des matières du manuscrit. Les feuillets, ainsi que la reliure, sont reproduits en couleur en grand format ( 78 feuillets au total, les ff. 2-5 et les ff. 73-77 contiennent une notice sur le manuscrit, établie par le duc d'Aumale, et la table, écrites en 1880). 